\title{
Do potatoes and tomatoes have a single evolutionary history, and what proportion of the genome supports this history? Flor Rodriguez ${ }^{1}$, Feinan $\mathrm{Wu}^{2}$, Cécile Ané ${ }^{3}$, Steve Tanksley ${ }^{2}$ and David M Spooner*1
}

\begin{abstract}
Address: ${ }^{1}$ USDA, Agricultural Research Service; Department of Horticulture, 1575 Linden Drive, University of Wisconsin-Madison, Madison, Wisconsin 53706-1590, USA, 2Department of Plant Breeding and Genetics, Department of Plant Biology, 248 Emerson Hall, Cornell University, Ithaca, New York 14853, USA and ${ }^{3}$ Department of Statistics, Department of Botany, 1300 University Ave., University of Wisconsin-Madison, Madison, Wisconsin 53706-1590, USA

Email: Flor Rodriguez - fdrodriguez@wisc.edu; FeinanWu - fw38@cornell.edu; Cécile Ané - ane@wisc.edu; Steve Tanksley - sdt4@cornell.edu; David M Spooner* - david.spooner@ars.usda.gov

* Corresponding author
\end{abstract}

Published: 7 August 2009

BMC Evolutionary Biology 2009, 9:191 doi:10.1186/147|-2148-9-191
Received: 2 February 2009

Accepted: 7 August 2009

This article is available from: http://www.biomedcentral.com/|47|-2/48/9/|9|

(C) 2009 Rodriguez et al; licensee BioMed Central Ltd.

This is an Open Access article distributed under the terms of the Creative Commons Attribution License (http://creativecommons.org/licenses/by/2.0), which permits unrestricted use, distribution, and reproduction in any medium, provided the original work is properly cited.

\begin{abstract}
Background: Phylogenies reconstructed with only one or a few independently inherited loci may be unresolved or incongruent due to taxon and gene sampling, horizontal gene transfer, or differential selection and lineage sorting at individual loci. In an effort to remedy this situation, we examined the utility of conserved orthologous set (COSII) nuclear loci to elucidate the phylogenetic relationships among 29 diploid Solanum species in the sister clades that include tomato and potato, and in Datura inoxia as a far outgroup. We screened 40 COSII markers with intron content over $60 \%$ that are mapped in different chromosomes; selected a subset of 19 by the presence of single band amplification of size mostly between 600 and 1200 bp; sequenced these 19 COSII markers, and performed phylogenetic analyses with individual and concatenated datasets. The present study attempts to provide a fully resolved phylogeny among the main clades in potato and tomato that can help to identify the appropriate markers for future studies using additional species.
\end{abstract}

Results: Among potatoes, when total evidence is invoked, one single predominant history is highlighted with complete resolution within and among the three main clades. It also supports the hypothesis of the North and Central American B-genome origin of the tuber-bearing members of Solanum sect. Petota and shows a clear division between A genomes in clades 3 and 4 , and $B$ genomes in clade $I+2$. On the other hand, when a prior agreement approach is invoked other potato evolutionary histories are revealed but with less support. These alternative histories could be explained by past hybridization, or fast rates of speciation. In the case of tomato, the analyses with all sequence data completely resolved 19 of 21 clades, for the first time revealed the monophyly of five clades, and gave further support for the recent segregation of new species from the former Solanum peruvianum. Concordance analyses revealed and summarized the extensive discordance among COSII markers. Some potential reasons for discordance could be methodological, to include systematic errors due to using a wrong model of sequence evolution, coupled with long branches, or mixtures of branch lengths within COSII, or undetected paralogy or alignment bias. Other reasons could be biological processes such as hybridization or lineage sorting.

Conclusion: This study confirms and quantifies the utility of using DNA sequences from different parts of the genome in phylogenetic studies to avoid possible bias in the sampling. It shows that II-18 loci are enough to get the dominant history in this group of Solanum, but more loci would be needed to discern the distribution of gene genealogies in more depth, and thus detect which mechanism most likely shaped the discordance. 


\section{Background}

The basic chromosome number in potatoes (sect. Petota), tomatoes (sect. Lycopersicum), and the most closely related outgroups (sects. Etuberosum, Juglandifolium, and Lycopersicoides) is $2 n=2 x=24$. Potatoes are alone in the group in possessing polyploids. Approximately $70 \%$ of the over 100 potato species are diploids, with most of the rest tetraploids $(2 n=4 x=48)$ and hexaploids $(2 n=6 x=72)$, with rare triploids and pentaploids [1].

Potatoes, tomatoes, and outgroups are characterized by relatively small chromosomes. Karyotypic and genomic analyses have included crossability success of interspecific combinations, hybrid sterility, hybrid viability, pollen fertility and in the degree of chromosomal homology [2-9]. Chromosome pairing relationships in interspecific hybrids and in polyploid potato species have been interpreted by genome formulae, although authors gave them different symbols. According to these hypotheses, five genomes ( $\mathrm{A}, \mathrm{B}, \mathrm{C}, \mathrm{D}$ and $\mathrm{P}$ ) are recognized in the tuberbearing species of section Petota. Genome symbol E was given to species of section Etuberosum based on the specificity of meiotic behavior and sterility of their diploid hybrids with the A-genome tuber-bearing potato species $[7,10]$. Symbol L was proposed for tomato (section Lycopersicon) on the bases of preferential chromosome pairing and clear-cut parental genome discrimination by using genomic in situ hybridization (GISH) and LLEE or artificial amphidiploids of tomato and S. etuberosum [11].

Wild and cultivated potatoes (Solanum L. sect. Petota) (see Additional file 1 for authors of taxa) grow from the southwestern United States to southern Chile. Hawkes [5] recognized 232 species in section Petota, and divided it into 19 tuber-bearing and two non-tuber-bearing series. He further divided these 19 tuber-bearing series into two superseries based on corolla morphology (superseries Stellata with stellate corollas and superseries Rotata with rotate corollas). He distinguished "primitive" and "advanced" forms of each superseries and recognized four groups based on morphological characters: primitive Stellata, advanced Stellata, primitive Rotata, and advanced Rotata. He hypothesized the evolution of the advanced Rotata morphology from primitive Stellata-like ancestors. He postulated that the ancestral wild potato species were diploid, possessed $\mathrm{B}$ genomes, produced white stellate corollas, and originated in North or Central America in the late Cretaceous to Eocene eras. Subsequent dispersal of one or more of these species to South America took place before the sinking of the Central American land bridge during the mid-Eocene to Pliocene eras, gradually leading to the evolution of species with A genomes and rotate corollas. He also postulated that when the bridge was restored in Pliocene times, a remigration of one or more of these diverged A genome species back into North and Central America allowed the hybridization and allopolyploidization with the native Mexican or Central American $\mathrm{B}$ genome taxa. This produced the tetraploid members of series Longipedicellata (AB). A second, comparatively recent migration of a second species (S. verrucosum, A genome) from South America formed the Demissa hexaploids $\left(\mathrm{A}_{1} \mathrm{~A}_{4}[\mathrm{~B}, \mathrm{C}, \mathrm{D}]\right)[5]$ by crossing with series Longipedicellata tetraploids and possibly other series. In North and Central America are also another group of allopolyploids, members of series Conicibaccata (AC), but only series Longipedicellata was designated $\mathrm{AB}$, and the source of the $\mathrm{C}$ and D genome donors of series Conicibaccata and Demissa is unknown. However, recent molecular clock data indicated that eggplant and tomato/potato shared a common ancestor approximately 14 MYA and potato and tomato 7 MYA [12]. So it seems unlikely that the timing for the events proposed by Hawkes really took place in the Cretaceous - Eocene eras but the events are still possible.

The latest taxonomic interpretation [13] recognized fewer species (190) and predicted even further reductions in species. Spooner et al. [14] used plastid DNA restriction site data and morphological data to reinvestigate the relationships of potatoes, tomatoes (former genus Lycopersicon), farther outgroups in Solanum, and other genera of the Solanaceae. Their results confirmed placement of all members of Hawkes's [5] tuber-bearing species into sect. Petota (90\% bootstrap), but the non-tuber-bearing species were shown to be outgroups although with very low support $(68 \%)$. Yet other plastid DNA restriction site marker data and DNA sequence data from plastids and singlecopy nuclear DNA supported these relationships [15-18].

Subsequent plastid DNA phylogenies documented section Petota (tuber-bearing) to be divided into four clades that often showed little relationship to Hawkes's taxonomic series (Figure 1) [19-21]. These clades contain: 1) North and Central American diploid species, with the exception of S. bulbocastanum, S. cardiophyllum, and S. verrucosum; 2) S. bulbocastanum, and S. cardiophyllum; 3) all examined members of series Piurana and some South American species belonging to other series ( $S$. andreanum, S. chancayense, S. immite, S. mochiquense of ser. Tuberosa; $S$. chomatophilum, S. colombianum, S. solisii, S. tundalomense of ser. Conicibaccata; S. huancabambense of ser. Yungasensia; S. sogarandinum of ser. Megistacroloba); 4) all remaining South American species, S. verrucosum from Mexico, and North and Central American polyploid species. Only two clades were highly supported, clade $1(100 \%)$ and clade 2 $(88 \%)$, these clades contained all species with $\mathrm{B}$ genome, but they did not resolve together and the monophyly of the $\mathrm{B}$ genome was not supported. Clades 3 and 4 were poorly supported (54 and 67\% bootstrap respectively), but their sister relationship was highly supported (96\%). Single-copy granule-bound starch synthase (GBSSI or 


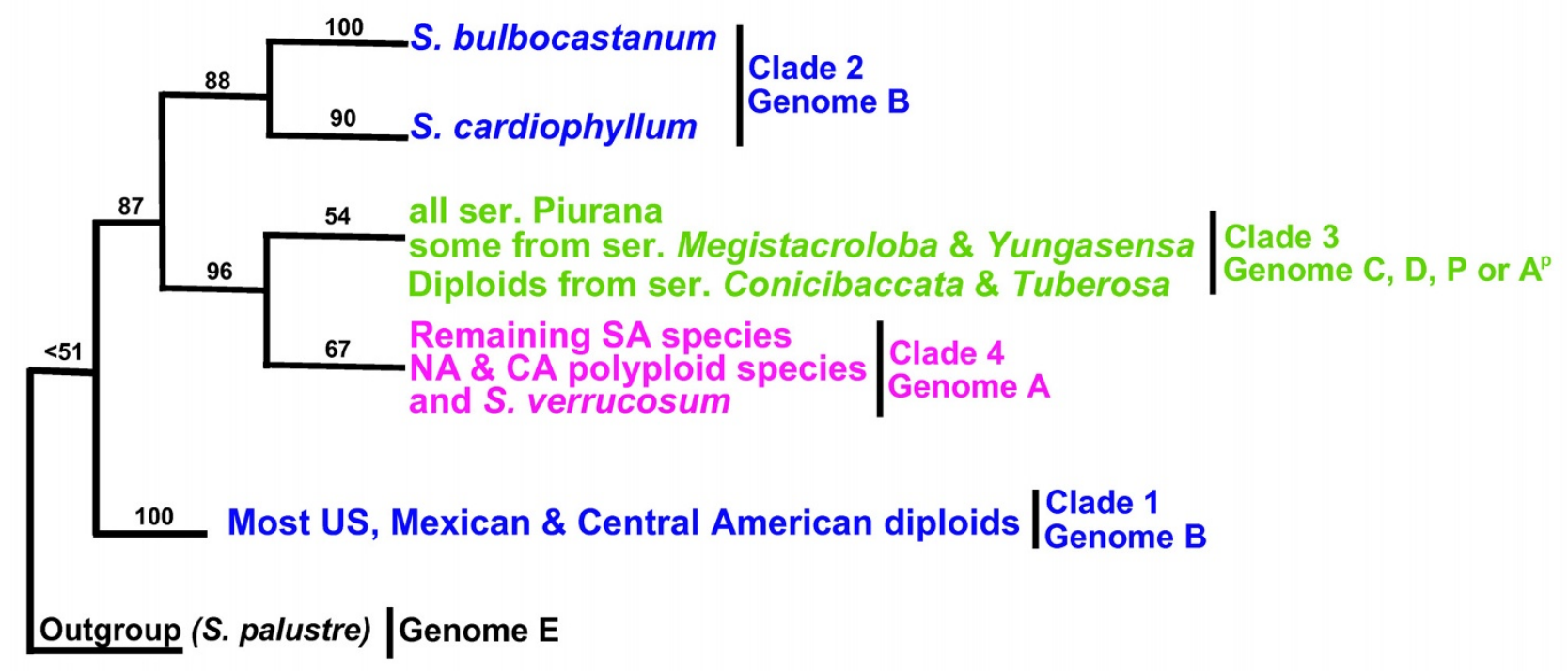

Figure I

Plastid clades of Solanum sect. Petota [19-21,60].

waxy) [22] and nuclear nitrate reductase gene data (NIA) [23] recovered the same four clades except united clades 1 and 2 as a single clade (72\% in waxy and $92 \%$ in NIA), the nuclear phylogenies recognized the monophyly of $B$ genome species (clade $1+2$ ), and supported allopolyploid origins for some of the polyploids with species from different clades. The main difference between the two nuclear phylogenies was the relationship among main clades; in NIA clade $1+2$ and 3 were sister in the most parsimonious tree although with very low support $(\leq 51 \%)$, and waxy could not show any close relationships among the clades.

Taxonomic interpretations in tomato (Solanum sect. Lycopersicon) differed widely depending upon whether morphological or biological species concepts were used [24]. Rick et al. [25] recognized nine species of tomatoes, based mainly by their ability to intercross, and divided them into two crossing groups. Peralta et al. [24] summarized morphological studies of tomatoes [18,26-30], increased the traditional nine species of Rick et al. [25] to 13 species, and recognized tomatoes within Solanum. Tomato has two endemic species in the Galápagos Islands, and weedy escaped forms of $S$. lycopersicum are distributed worldwide. The remaining species and immediate tomato outgroup sections Juglandifolia (two species) and Lycopersicoides (two species) are endemic to western South America from Ecuador to northern Chile.

Peralta et al. [24] interpreted the many and sometimes conflicting morphological and molecular data sets to rec- ognize four informal "species groups" within sect. Lycopersicon: the "Lycopersicon species group" including the four red to orange colored fruited species $S$. cheesmaniae, $S$. galapagense, S. lycopersicum, and S. pimpinellifolium; the "Neolycopersicon species group" containing only $S$. pennellii, the "Eriopersicon species group" containing $S$. chilense, S. corneliomulleri, S. habrochaites, S. huaylasense, S. peruvianum and, the "Arcanum species group" including $S$. arcanum, S. chmielewskii, and S. neorickii. They recognized sect. Juglandifolia as the sister group to sect. Lycopersicon.

In the past, comparative anatomy, cytogenetics, ecology and morphology had been used to infer phylogenetic relationships among taxa. Lately, with the development of molecular techniques, many fragments of the genome have been used in phylogenetic inference and multiple data sets have become available. As a result, phylogenetic studies now usually involve data sets from different gene regions, or different marker systems, or molecular and morphological data sets. There has been an active and controversial debate over the best ways to derive a phylogeny that incorporates all existing data. There are three different traditional approaches that have been used to analyze data from different sources: taxonomic congruence, character congruence and the prior agreement approach. They all seek to maximize evidence, the first one from the relationships (cladograms) using the summaries of data as evidence, and the other two derived directly from characters using data observation as evidence [31]. 
Proponents of the consensus approach argue that partitions should not be combined before estimating the phylogenetic tree; rather, the trees should be estimated separately from each partition and combined using taxonomic congruence [32]. The decision to keep data sets separate generally reflects a hypothesis that either 1) different evolutionary processes are acting on different data sets, or 2) different data sets reflect different evolutionary histories [33].

Character congruence, also known as the total evidence approach, involves all the data available for a group of terminal taxa. The goal is to seek a single, best-fitting hypothesis, which in cladistics involves maximizing character congruence [31]. The prior agreement approach or "conditional combination" tests for character incongruence before analysis, and only combines the data when no significant character incongruence exists between partitions.

Farris et al. [34] proposed the Incongruence Length Difference (ILD) test that many researchers use to assess whether or not data sets should be combined. The idea is to determine if there is more incongruence between data sets than is expected between similarly sized random partitions of a homogeneous data set.

Baum [35] proposed that the identification of the primary concordance tree (PCT) could be a valuable summary of the dominant phylogenetic history among a group of organisms. The PCT is composed of clades with higher concordance factors $(\mathrm{CF}$, proportion of the genome for which a given clade is true) than any contradictory clade. Ané et al. [36] developed a Bayesian-based methodology that estimates the distribution of evolutionary histories within a multi-gene data set and summarizes the results allowing genealogical information from one gene to influence our estimates of another gene's genealogy. It also allows the identification of genes with outlier genetree topologies that permits estimation of the proportion of the genome that was transferred during a possible introgression event. Baum [35] pointed out the possible outcomes that can arise if reticulation events had happened during the evolutionary history of a group of organisms. If a single event of horizontal gene transfer (HGT) had occurred, one primary history and one minor history are expected. Under lineage sorting or introgression, one primary history and co-minor histories are expected. But, if hybridization occurs two co-primary histories are expected. Thus, the concordance approach is considered a modified consensus tree method that allows the identification of different phylogenetic histories in the face of reticulation, where estimated CFs are metrics that give an indirect measure of reticulation. Furthermore, it can be assumed that high CFs provide evidence that relationships among the organisms under study have been mostly divergent, and that low CFs are indicative of reticulate evolution. Baum [35] stressed that the acquisition of a divergence structure increases gradually as a result of gene lineage extinction in reproductively isolated populations or demes. Thus, the speciation process reaches its ultimate point when a CF of 1 is reached. Finally, he stated that a clade which has a CF that is greater than all contradictory clades has some genealogical unity that indicates a history of genetic isolation and suggested that this clade can be formally named.

Recently, single- to low-copy nuclear DNA markers have been explored for phylogenetic reconstruction. Here we test a specific subset of these markers called conserved ortholog set II (COSII) markers in the sister clades potato and tomato [37]. Orthologs are genes sharing a common ancestor by descent, in contrast to paralogs that are duplicated copies within a genome through polyploidization or tandem duplications [38,39].

The purpose of our study is to test a diverse range of COSII markers and data analyses for phylogenetic reconstruction in the sister clades tomato and potato. The phylogenetic relationships between and among species from these two groups have been the subject of study by many researchers, but these relationships remain unresolved because of the use of a limited number of molecular markers. Our study was greatly aided by COSII conversion into a set of consensus PCR primers that amplify these orthologues in the Solanaceae, referred to as universal primers for euasterid I (UPA) [37]. UPAs are designed to amplify either intronic regions (iUPA primers) that provide the polymorphism needed for the proposed tomato and potato study, or exonic regions (eUPA primers) that are more appropriate for comparisons of more distantly related species. Our study uses many more molecular markers than prior phylogenetic studies in the tomato and potato clades. It does not attempt to provide a definitive study of the evolutionary relationships within these clades, but rather to identify appropriate markers for future studies that should incorporate a wider species sampling. Our approach consists of examining 1) diverse markers on all 12 linkage groups, 2) amplification of a single band (in diploids) of representative taxa, 3) markers with length between 600-1200 bp that amplify with single pass sequencing, and 4 ) markers with over $60 \%$ intron content appropriate for this taxonomic level of closely related species.

\section{Results}

\section{Allelic variation and sequence alignment}

Of the 30 species analyzed, four tomato species had two alleles: S. chilense and S. huaylasense in $\operatorname{COS} 5 \mathrm{c}$ and COS13b, S. peruvianum and S. habrochaites in COS7b, S. huaylasense in COS10b, S. peruvianum in COSX2 and 
COS11b, S. chilense in COS1b; S. chilense, S. peruvianum and $S$. habrochaites in COS8b, and S. chilense, S. peruvianum and $S$. huaylasense in COS15b (16 cases in total). In four of these 16 cases alleles from the same species form a clade; in four cases alleles formed polytomies; and in eight cases alleles from the same species formed a clade with another species [40].

Complete sequences (total missing data less than 0.3\%) were generated for the 19 COSII. In general, the farthest outgroups, Datura inoxia and S. dulcamara, showed the longest sequence and the tomato species and their closest outgroups showed more gaps in aligned sequences in comparison with potato [40].

\section{Model selection}

In general, likelihood models that account for rate variation, allowing for gamma-distributed rate variation among sites $(\Gamma)$, resulted in the greatest increase in Maximum Likelihood (ML). In more than $90 \%$ of the cases the HKY model that includes five parameters best fitted the data [40]. In cases where the two criteria for selection chose different models, the model that is implemented in Mr. Bayes was preferred.

\section{Phylogenetic analysis of individual loci}

Analysis of individual COSII sometimes showed incongruent results. To illustrate this we discuss our data using maximum parsimony analysis in potato and direct the reader to [40] for details in the tomato and complete data sets and with maximum likelihood and Bayesian inference. In the potato data set the number of parsimony informative sites per individual COSII varied from 13 to 64; in tomato, from 20 to 286; and for the potato and tomato data set from 46 to 317 . All data sets showed high consistency, retention and rescaled consistency indices, with consistency indices ranging from 0.753 to 1.000 , and rescaled consistency indices ranging from 0.612 to 1.000 . There was a moderate level of homoplasy (calculated by $\mathrm{H}$ $=1-\mathrm{CI}$ ) with less than $25 \%$ for all loci.

In the potato data set seven of the 12 COSII sequenced supported the three main potato clades as a monophyletic group. In eight of the 12 COSII clade $1+2(S$. bulbocastanum, S. polyadenium, S. stenophyllidium, S. trifidum) was monophyletic with bootstrap support over 54\%; in three of the 12 COSII, clade $1+2$ failed to resolve into a distinct clade; one COSII placed $S$. polyadenium outside of clade $1+2$. When we forced the monophyly of clade $1+2$ for this COSII, the shortest tree was ten steps longer than the unconstrained tree, which was significant by the Templeton Test ( $p=0.0016-0.0075)$ and the monophyly of this clade was rejected [40].
Clade 3 (S. albornozii, S. andreanum) had bootstrap support more than $50 \%$ in nine of the 12 COSII; one COSII failed to group these species in their own clade, and two COSII grouped one of the two species in clade 4 . Forcing these species to be monophyletic resulted in trees only three and two steps longer than the unconstrained tree, and the Templeton test failed to reject their monophyly ( $p$ $=0.3657$ and $p=1$ ). Thus, stochastic noise alone can explain the misplacement of these species.

Clade 4 (S. brevicaule, S. raphanifolium, S. verrucosum) had bootstrap support more than $59 \%$ in ten of the 12 COSII; in the remaining two COSII $S$. raphanifolium did not form a clade with the other two species, and trees forcing all three species to group together were only one and three steps longer than the Maximum Parsimony (MP) unconstrained tree. The Templeton test failed to reject their monophyly and revealed that the entire clade 4 became unresolved in trees that were one and three steps longer than the MP tree. This indicates that the observed nonmonophyly is not significant $(p=0.8635$ and $p=0.0833-$ 0.3173 respectively) [40].

Regarding the relationships among the three main clades, four of the 12 COSII supported clade $1+2$ as sister to the rest of potatoes, with bootstrap support ranging from 59$100 \%$. Three COSII placed clade 3 as sister to the rest of potatoes and only two of these three COSII gave bootstrap support of $69 \%$ and $90 \%$. Two COSII placed clade 4 as sister to the rest of potatoes with a bootstrap support of $60 \%$ and $100 \%$ respectively. The remaining three COSII did not support any of the three basal relationship alternatives in their most parsimonious trees. Attempts to force species to follow either of these three possibilities were not rejected for $\operatorname{COS} 2 \mathrm{c}$, because constrained trees were only four or five steps longer than the MP unconstrained tree. In contrast, COS5 could not reject clade $1+2$ as sister to the other potatoes, and COS5c could not reject clade 3 species as sister to the others.

\section{Combined data analyses}

We explored three approaches to combine the data: total evidence, prior agreement, and the consensus approach.

\section{Total evidence, potato data set}

We concatenated the 12 COSII of the potato data set into a data matrix of 10,886 characters, with introns accounting for $85 \%$ of the total concatenated length. The concatenated alignment contained 1,219 (11.2\%) variable sites, of which 519 (4.8\%) were parsimony informative. Phylogenetic analyses of the concatenated sequence using MP, $\mathrm{ML}$ and BI, all yielded a single fully resolved tree with high bootstrap support and Bayesian posterior probability (Figure 2a). 


\section{Total evidence, tomato data set}

Eighteen COSII were concatenated; the data matrix contained 15,709 characters, $82 \%$ of these representing introns, with the total data set containing 4,022 variable sites of which 1,910 (12.2\%) were parsimony informative. MP, ML and BI supported at least the same 18 of 21 nodes as completely resolved with very high bootstrap values (MP: 90-100\%, ML: 99-100\%) and posterior probability $(P P=1)$ (Figure 3$)$. Two nodes were not very well supported in MP, ML and BI, one of them was the placement of the clade formed by S. arcanum-S. chmielews-
kii-S. neorickii (51\% in MP, $<51$ in $\mathrm{ML}$, and 0.55 in $\mathrm{BI}$ ). In $\mathrm{MP}$ and $\mathrm{BI}$ this clade was resolved with the red-orange tomatoes (S. cheesmaniae, S. galapagense, S. lycopersicoides, S. pimpinellifolium), and in $\mathrm{ML}$ it resolved as sister to a clade containing the red-orange tomatoes and S. huaylasense. The second unresolved node was the placement of the clade formed by S. chilense-S. corneliomulleri-S. peruvianum; ML and BI revealed that this clade was closer to the red-orange tomatoes than the clade formed by $S$. habrochaites-S. pennellii (73\% in ML and 0.80 in $\mathrm{BI}$ ). On the other hand, MP showed that S. habrochaites-S. pennellii a

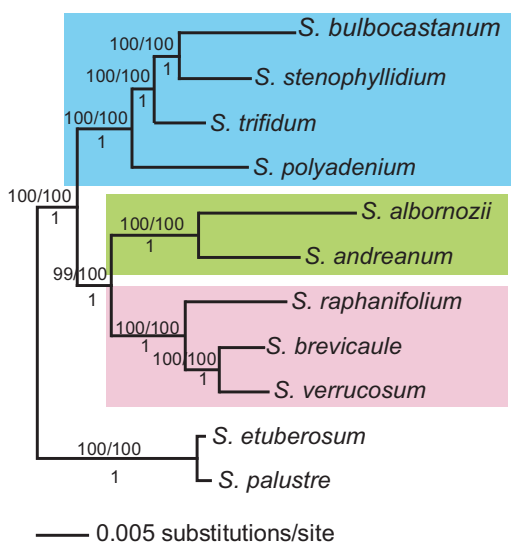

b

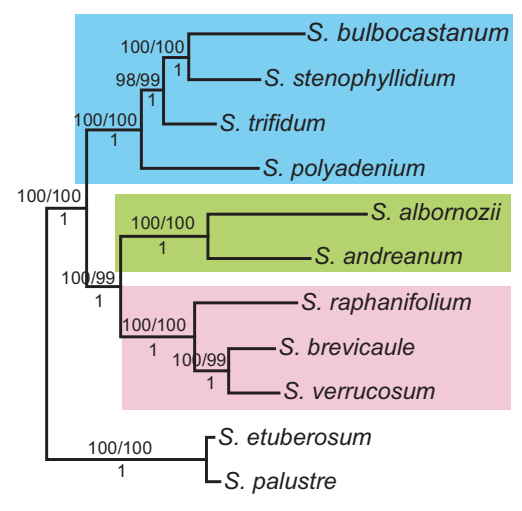

C

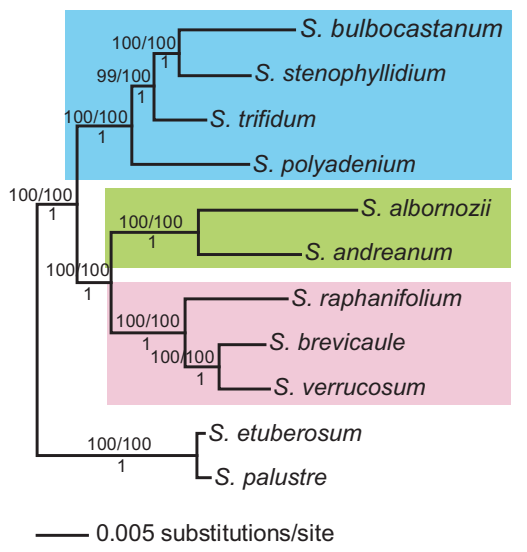

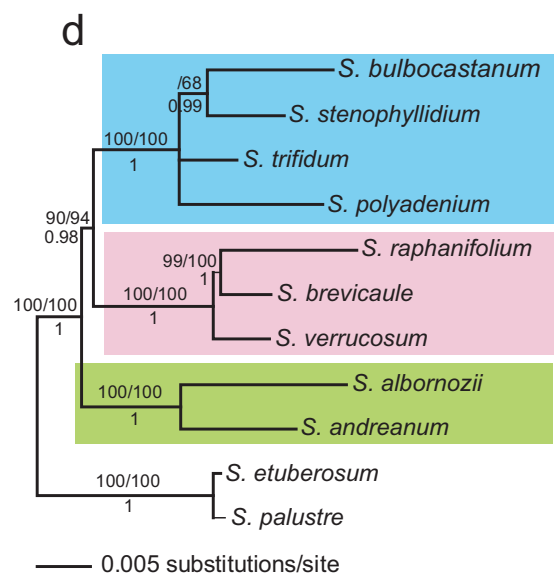

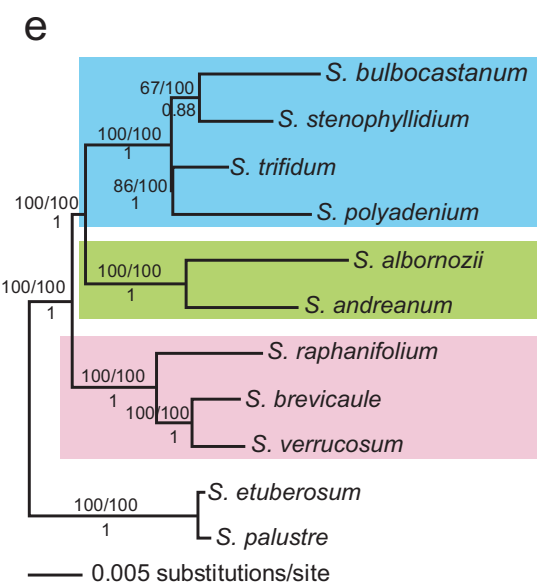

\section{Figure 2}

Potato Bayesian phylogram based on a combined analysis. Using 12 COSII sequences in (a), six COSII (COS 9 , COS $9 b, \cos I I, \cos 3, \cos 8$ and $\operatorname{COS} 3 c$ ) sequences (b), three $\operatorname{COSII}(\operatorname{COS} 9, \cos 9 b$ and $\operatorname{COS} I 1)$ sequences (c), with COS7b (d), and with two COSII (COSIOb and COSIc) (e). Branch lengths are drawn in proportion to the estimated number of substitutions per site and represent an average of the branch length of all trees sampled in the Markov chain that have that branch. Bootstrap values higher than $50 \%$ are indicated above branches, the first value refers to Maximum Parsimony and the second to Maximum Likelihood analyses; below branches are the posterior probability values. Species belonging to clades I+2 are in blue shadow, species in clade 3 in green shadow and species in clade 4 with pink shadow. 


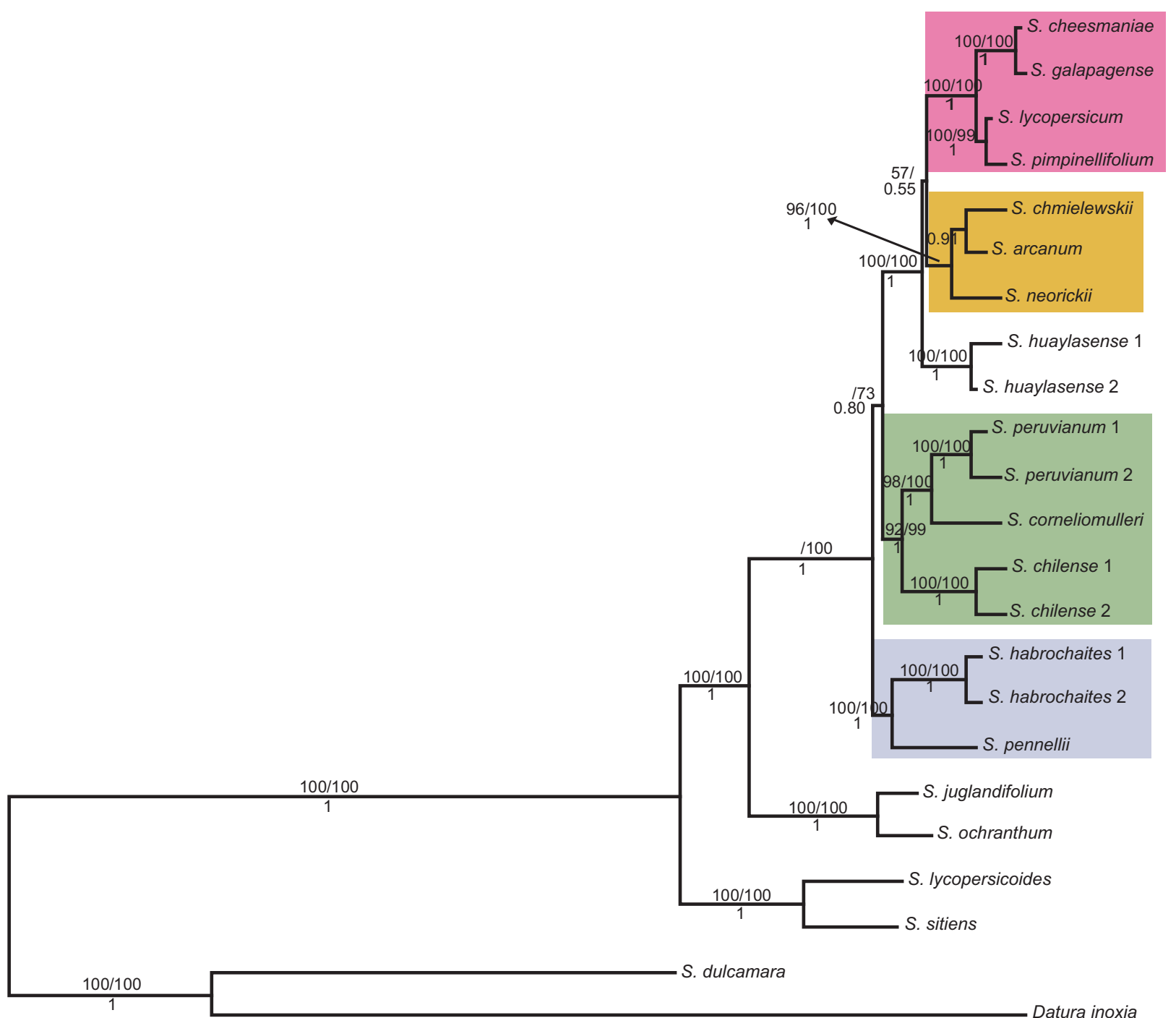

\section{Figure 3}

Tomato Bayesian phylogram based on a combined analysis of 18 COSII sequences. Datura inoxia and S. dulcamara were used as outgroups. Numbers after the species name indicate allelic variants. Support values are placed as in Figure I. Clades with many species have a background for helping follow the results and discussion.

was closer to the red-orange clade than the clade $S$. chilense-S. corneliomulleri-S. peruvianum (55\%). Finally, $\mathrm{MP}$ and ML resolved S. chmielewskii and S. neorickii with very low support $(<51 \%)$. On the other hand, BI resolved $S$. arcanum and $S$. chmielewskii with a posterior probability of 0.91 ; the terminal branch that resolved S. arcanum-S. chmielewskii-S. neorickii had 96\%, 99\% (bootstrap) and 1 (posterior probability) support in MP, ML and BI respectively.
Total evidence, potato and tomato data set

After the concatenation of 11 COSII, the matrix contained 11,566 characters; 3,006 were variable and 1,799 (15.6\%) were parsimony informative. Bayesian inference showed a completely resolved phylogeny. On the other hand, both MP and ML had two nodes with very low support $(\leq 51 \%)$ : 1) the placement of the clade with $S$. arcanum, $S$. chmielewskii, and S. neorickii, and 2) the node that showed relationships among these three species. Additionally, in 
MP the potato clade had only $57 \%$ bootstrap support (Figure 4).

\section{Prior agreement, potato data set}

A prior agreement approach combines only congruent data and excludes data partitions with a significant level of incongruence, as they can introduce error that can obscure reliable data and lead to erroneous topologies [41,42]. We explored the congruence of the different gene phylogenies in potato using ILD tests. From the 12 original COSII in potatoes, 66 pairwise comparisons were made with a level of significance of $0.00076(=0.05 / 66)$, and nine of them showed a high level of discordance $(p=0.0006)$. Three of these COSII (COS2c, COS5c and COS7b) counted for eight of these nine discordances $(p=0.0004)$, and the last one was between COS11 and COS10b $(p=0.0006)$.

Through reiterative analyses we proceeded to eliminate discordant COSII and constructed a set of six COSII that were highly congruent and produced highly resolved topologies similar to the entire concatenated data set and named this "6COScon" (COS 9, COS 9b, COS 11, COS 3, COS 8 and COS 3c) Rodriguez [40]. MP, ML, and BI of $6 \mathrm{COScon}$ gave the same phylogeny as the 12 COSII combined with $100 \%$ of bootstrap in all nodes except one that was supported at 99\% (Figure 2b).

We further explored a minimum number of COSII to be used in a large number of species without losing resolution by further reducing the "6COScon" to three COSII by choosing the best three by two criteria: 1) length of the sequence, and 2) number of parsimony informative sites and called this "3COSa" (COS9, COS9b, COS11). MP, $\mathrm{ML}$, and Bayesian analyses produced phylogenetic results almost identical to the 12 COSII set (Figure 2c).

\section{Consensus approach, potato data set}

Figure 5 shows the potato primary concordance trees and Figure 6 shows the concordance factors of all three resolutions for the placement of the main potato clades. With all three choices of prior $(\alpha=1,10$ and infinite) there was over $95 \%$ confidence that clade $1+2$ (CF $10.16=85 \%$ of COSII), clade 4 (CF $11=92 \%$ ) and clade $3($ CF $10=83 \%)$ formed clades for the majority of COSII. However, each of the three resolutions for the placement of those clades received concordance factors below 50\% with over 95\% credibility: the discordance among COSII markers was inferred to be real and strong. With all priors, the credibility intervals for the CF of all three resolutions (Figure 6) overlapped, therefore, it is still uncertain which placement is favored by the largest proportion of COSII.

\section{Consensus approach, tomato data set}

In the first concordance analysis performed with the tomato data set, the tomato clade was supported as mono- phyletic for almost all COSII in all runs and with all $\alpha$. Results from $\alpha=1$ and 10 placed sect. Lycopersicoides as the closest tomato outgroup to the tomato clade with just $50 \%$ of COSII supporting this relationship (9.31 and 9.22 COSII respectively); the other $50 \%$ of the COSII supported sect. Juglandifolia as the closest tomato outgroup. On the other hand, for $\alpha$ infinite, which corresponds to assuming that all gene trees are independent, and no concordance is assumed a priori, sect. Juglandifolia was placed as the closest tomato outgroup for only $40 \%$ of the COSII (7.21 COSII); sect. Lycopersicoides was supported as the closest outgroup to tomato for $32.5 \%$ of COSII $(5.85$ COSII). Section Juglandifolia and Lycopersicoides resolved together in only $9.3 \%$ of COSII, and the remaining $18 \%$ of COSII supported other relationships that could be considered as noise. Even though sect. Lycopersicoides was supported by a little more than $50 \%$ of the COSII as the closest outgroup to tomato with $\alpha=1$ and 10; and sect. Juglandifolia was supported by at least $40 \%$ of the COSII and by more COSII than any other contradictory clade with $\alpha$ infinite, the confidence intervals for all these $\mathrm{CF}$ overlapped. We conclude that sect. Juglandifolia and sect. Lycopersicoides are the closest tomato outgroups but concordance analysis cannot distinguish which is sister to the tomato clade for most of the COSII markers. Given that we have two primary histories that have the support of $50 \%$ of the genes with $\alpha=1$ and 10 , hybridization could be invoked as the main driving force [35] but since more than two histories are revealed with $\alpha$ infinite more testing of the concordance approach should be done and more genes should be sampled before we can conclude with confidence that hybridization or introgression was the main driving force (Figure 7).

Results from the second tomato concordance analysis placed the clade consisting of $S$. habrochaites and S. pennellii as sister to the rest of tomatoes, indicating that those are the most divergent group; the CF was 30\% (5.38 COSII) with $\alpha$ infinite, $63 \%$ (11.34 COSII) for $\alpha=10$ and $66 \%$ (12 COSII) for $\alpha=1$, and the credibility intervals for the CF of conflicting clades did not overlap. Thus, we conclude that $S$. habrochaites and $S$. pennellii are the most divergent tomatoes and are monophyletic (Figure 7). This analysis also placed $S$. corneliomulleri with $S$. peruvianum in all the runs with CF of $33 \%$ to $47 \%$ of COSII, and $S$. chilense outside of the clade conformed by $S$. corneliomulleri-S. lycopersicum-S. peruvianum, with CF ranging from $18 \%$ to $32 \%$ (Figure 7 ).

In the last concordance analysis with the tomato data set, all 18 COSII supported $S$. huaylasense as the sister to two clades, one formed by the red-orange colored fruit tomatoes (S. cheesmaniae, S. galapagense, S. lycopersicoides, S. pimpinellifolium) and the other formed by three species, $S$. arcanum-S. chmielewskii-S. neorickii; it also resolved $S$. 


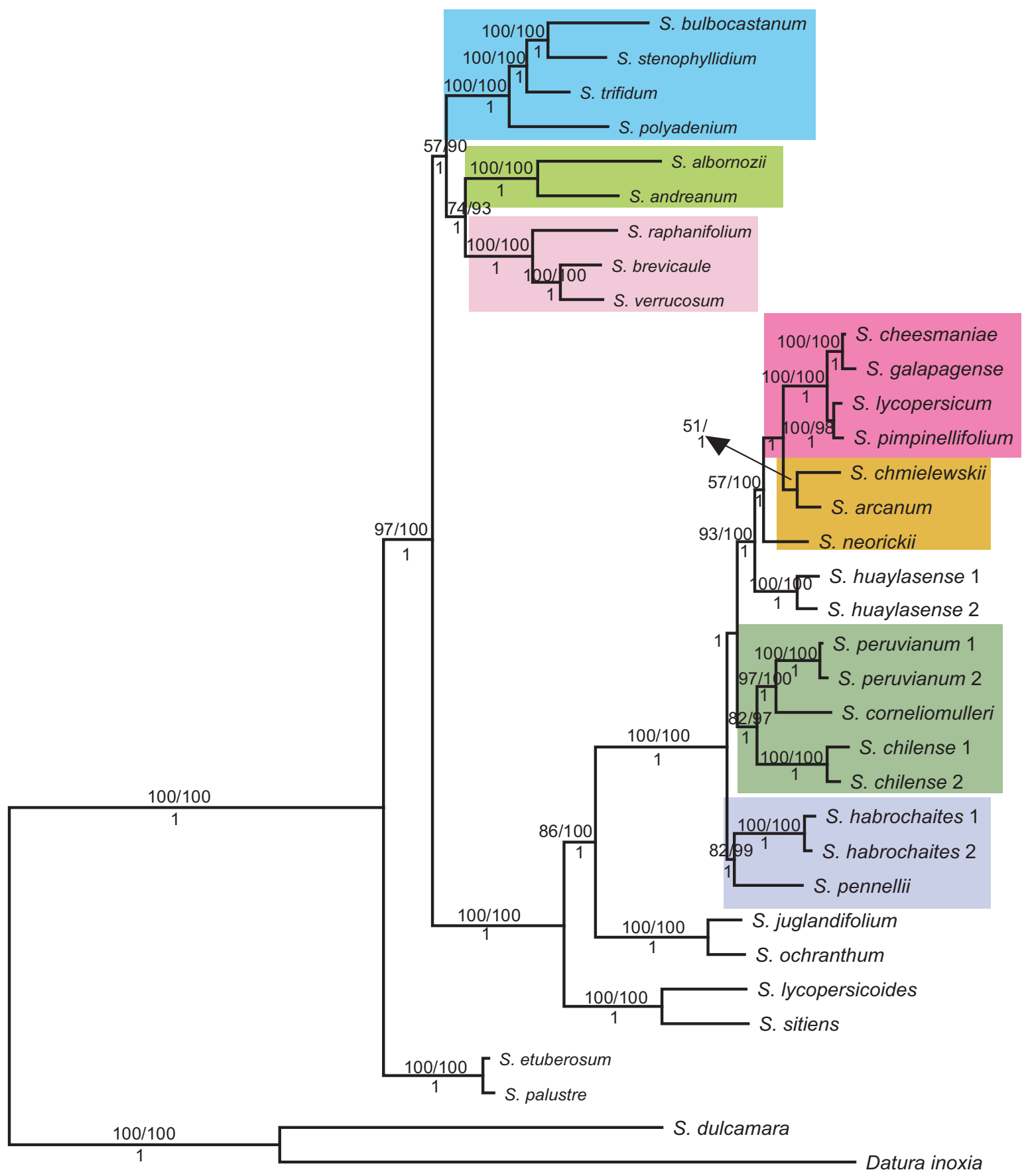

0.005 substitutions/site

\section{Figure 4}

Bayesian phylogram based on a combined analysis in potato, tomato and outgroups. Datura inoxia and S. dulcamara were used as outgroups. Numbers after the species name indicate allelic variants. Support values are placed as in Figure I. Shading as in Figures 2, 3. 

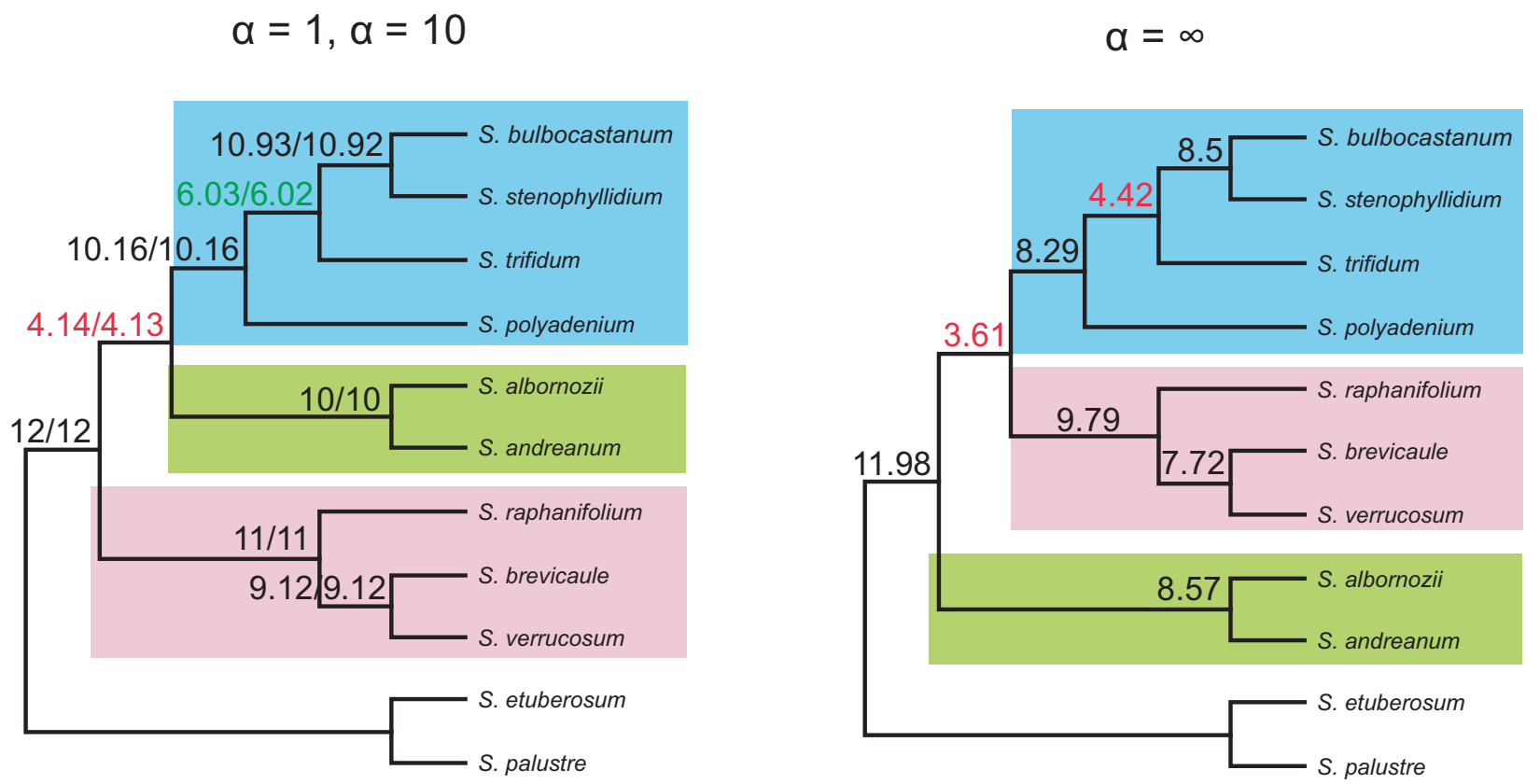

\section{Figure 5}

Results from potato Bayesian concordance analysis using 12 COSII. Number of COSII supporting each clade indicated above branches (concordance factors), in red are clades supported by less than $50 \%$ of the COSII; in green clades supported by almost $50 \%$ of COSII and in black clades supported by more than $50 \%$ COSII. Shading as in Figure 2.

\section{History 1}

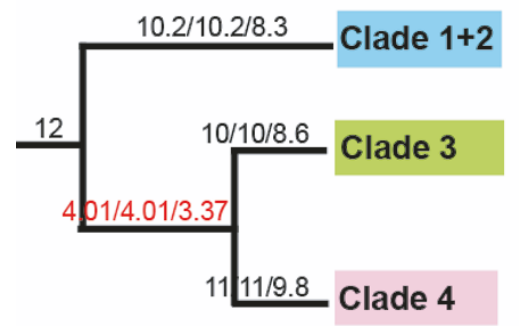

History 2

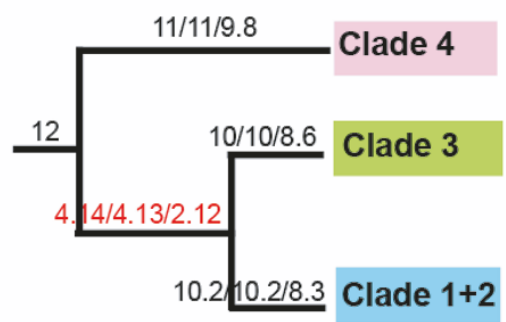

History 3

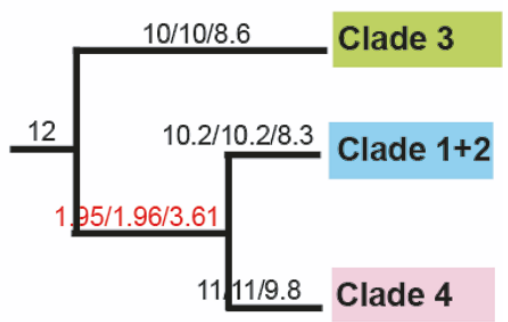

\section{Figure 6}

Summary of the Bayesian concordance analysis in potatoes performed with 12 COSII. Above branches are the concordance factors for $\alpha=1,10$ and infinite respectively. The numbers supporting the branches in red are clades supported by less than $50 \%$ of the COSII and in black clades supported by more than $50 \%$ COSII. Shading as in Figure 2. 


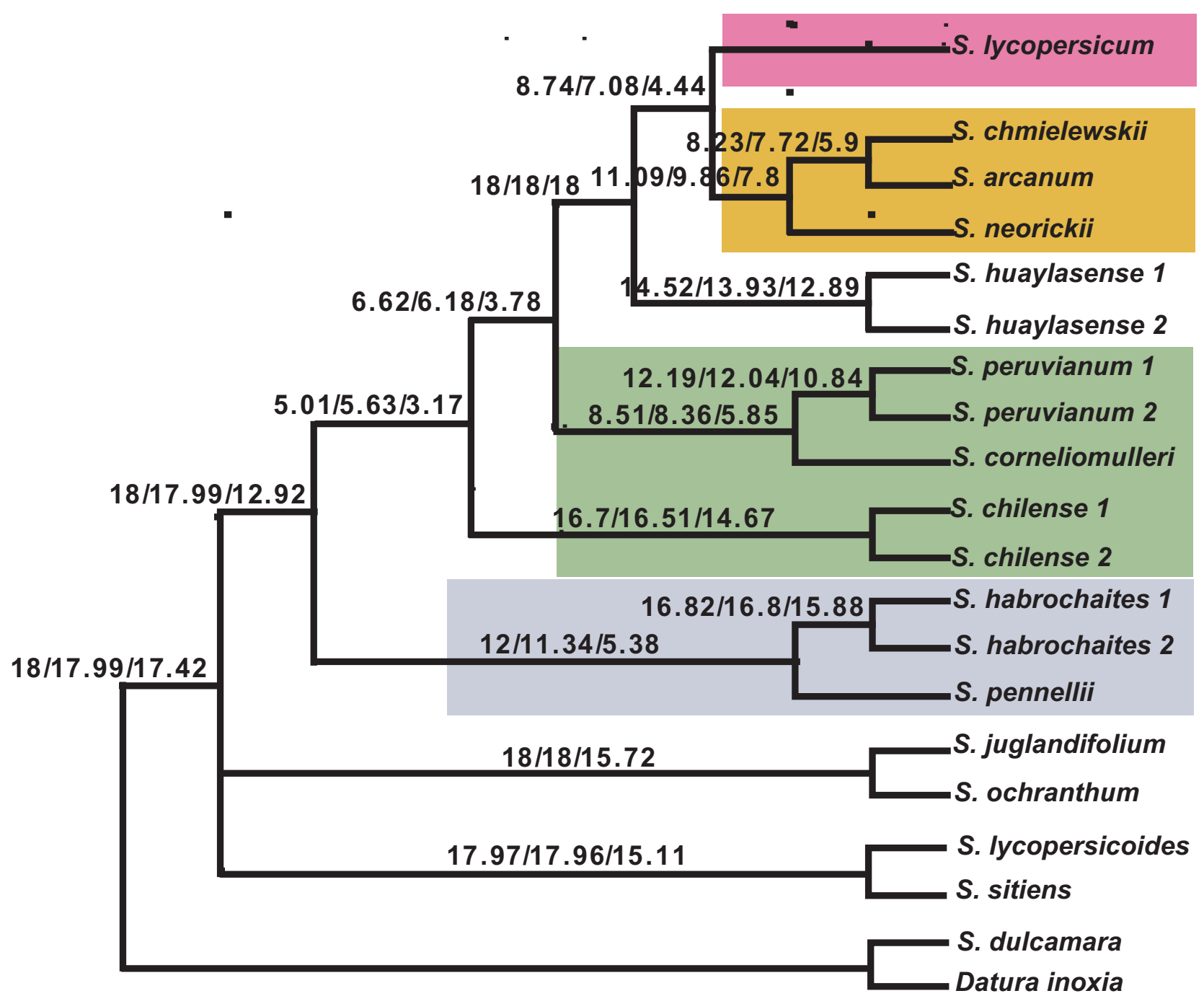

Figure 7

Summary of the Bayesian concordance analysis in tomatoes with all I 8 COSII. Above branches are the concordance factors for $\alpha=1,10$ and infinite respectively. Shading as in Figure 3.

chmielewskii with $S$. arcanum in all three $\alpha$ values (Figure 7).

\section{Discussion}

As was pointed out in the background, all three approaches summarizing multiple data sets seek to maximize evidence, but there are questions about when each approach should be applied. Combined analysis of multiple data sets is justified when each data set has evolved under the same underlying history, in which differences in the estimated tree are due only to sampling error or model mis-specification [35]. Under this assumption, the combined phylogenetic analysis improves the signal to noise ratio. It potentially allows for more accurate estimation of the single shared genealogy. It also produces a more accu- rate phylogeny than from a consensus approach. But, in cases where genes have tracked more than one underlying history, some of the differences among data sets would not be due to sampling error, but to genealogical discordance. In this case we may wish to estimate the primary history with information quantifying the extent to which different genes have followed that history. That primary history can be obtained using a combined analysis if there are similar amounts of phylogenetic signal in each sampled gene. But, because combined analysis assumes that there is only one evolutionary history, the discordance is assumed to be caused by homoplasy, and when reticulation has occurred the inferred tree may not resemble any of the underlying histories. In such a case, Bayesian concordance analysis (BCA) would be a better procedure to 
use, because it does not assume one single evolutionary history. Rather, it allows us to make statements of statistical confidence in the estimated concordance factors by taking into account the prior evidence of discordance, uncertainty in gene tree estimates, and the number of genes sampled. It also allows the investigation of potentially interesting biological processes, such as incomplete lineage sorting, hybridization, and lateral gene transfer [36]. For this reason, BCA is becoming a tool to analyze genealogies that are neither fully reticulate nor fully divergent [35]. Therefore, we followed all three approaches to get insights into the evolutionary processes in tomato and potato.

COSII analyses support many aspects of prior phylogenetic interpretations of potato and tomato, show some new relationships, but most notably, when total evidence is invoked, one single predominant history is highlighted with complete resolution in potato (Figure 2a) and nearly so in tomato (Figure 3). In potato, the four clades discovered from plastid DNA restriction site data $[19,21]$ is supported except, like waxy sequence data [22] and NIA sequence data [23] clades 1 and 2 are united into a single clade. Results from total evidence highly support the hypothesis of a North and Central American B-genome origin of the tuber-bearing members of Solanum section Petota, as it was shown to be sister of the rest of potatoes. It resolves the controversy among all previous individual gene sequencing studies that showed different relationships among main clades. On the other hand, when a prior agreement or consensus approach was invoked, other evolutionary histories in potatoes are revealed but with less support (Fig 2d, 2e, Figures 6,7). Of interest is that the branches showing these two alternative histories (Figure $2 \mathrm{~d}, 2 \mathrm{e}$ ) are shorter than the branch showing the predominant evolutionary history (Figure 2a). These alternative histories could be explained by past hybridization events or fast rates of speciation.

In tomato, 19 of the 21 nodes are completely resolved and for the first time this study highly supports the monophyly of five clades: 1) a clade that includes S. arcanum-S. chmielewskii-S. neorickii, 2) a clade conformed by $S$. chilense-S. corneliomulleri-S. peruvianum, and the sister relationship between S. corneliomulleri and S. peruvianum; 3 ) a clade formed by $S$. habrochaites-S. pennellii as basal in tomatoes, 4) a clade that includes $S$. cheesmaniae and $S$. galapagense, and 5) a clade formed by S. lycopersicum and S. pimpinellifolium (Figure 3). COSII data also clearly support the segregation of $S$. peruvianum sensu lato into at least three species, S. arcanum, S. huaylasense, S. peruvianum $+S$. corneliomulleri (on the same clade) as a possible single species, or all four of these species, following Peralta et al. [43]. The data show S. arcanum and S. huaylasense to be very distinct from $S$. corneliomulleri and $S$. peruvianum that were on the same clade (Figure 3 ). The two branches that remain unresolved are the placement of the clade S. arcanum-S. chmielewskii-S. neorickii and the relationship among these three species. Both of these branches are very short (Figure 3 ), indicating the possible need for additional markers as was pointed out by Zou et al. [44], who showed the need for 142 gene sequences to resolve two small branches in the phylogeny of rice. The sister group relationships of sect. Lycopersicon to sect. Juglandifolia and to sect. Lycopersicoides were completely resolved thereby clarifying ambiguities in previous studies.

Concordance analyses in tomatoes reveal the same relationships as total evidence, but the monophyly of the clade with S. chilense-S. corneliomulleri-S. peruvianum is not supported and the placement of sect. Juglandifolia or sect. Lycopersicoides as the closest tomato outgroup remained unresolved. Furthermore, concordance analyses reveal and summarize the extensive discordance among COSII markers. This discordance is precisely why a large sample of nuclear loci was necessary for the reconstruction of a robust phylogeny in potato and tomato. Some potential reasons for discordance could be methodological, to include systematic errors due to using a wrong model of sequence evolution, coupled with long branches, or mixtures of branch lengths within COSII, or undetected paralogy or alignment bias. Other reasons could be biological processes such as hybridization or lineage sorting or fast speciation.

In the complete data set, where potatoes and tomatoes are analyzed together, the sister relationship between the potato and tomato clades is highly supported in all analyses and sect. Etuberosum is supported as sister to both (100\%, 100\% and 1), confirming these controversial relationships as was first shown by Spooner et al. [14]. Additionally, our study highlights the importance of high intron content (more than 60\% in this study), and PCR amplification length between 600 and 1000 bp to be useful to investigate relationships among potato and potato. It shows the importance of intensive screening of COSII primers to maximize their utility in potato and tomato and allows us to propose the use of a reduced set of COSII primers for maximum efficiency. For example, for the major clades of sect. Petota, three COSII (COS9, COS9b and $\cos 11$ ) were enough to reveal the predominant history with high support, and we suggest beginning with these COSII in future studies in potato. This suggestion has to be taken with caution because when more taxa and more accessions per taxon are sampled the resolution can be reduced. Finally, the utility of gaps as additional characters in phylogenetic studies is not questionable but it is advisable to use them when their inclusion does not 
increase homoplasy. However, in this study, gap characters usually increased phylogenetic signal.

\section{Conclusion}

COSII sequence data are useful for potato and tomato phylogenetic studies. Intron contents more than $60 \%$ were the best to investigate relationships within this group of closely related species. When total evidence is invoked, a well-supported predominant history is revealed in both potato and tomato. In the case of potato, with the prior agreement and consensus approaches, two additional possible histories were revealed, although with less statistical support. We show that 11-18 loci are enough to get the dominant history in potato and tomato respectively, but a reduced set of three COSII provide the same phylogeny in potato. Finally, we determined that there is not a single evolutionary history for potato and tomato, as at least three different possible histories were revealed. More loci would be needed to discern the distribution of gene genealogies in more depth, and thus detect which mechanism most likely shaped discordance among individual COSII.

\section{Methods \\ Plant Materials and DNA Isolation}

One diploid genotype from nine wild potato species (sect. Petota) representing all four plastid clades, all 13 wild tomato species (sect. Lycopersicon), both species of sect. Juglandifolia, both species of sect. Lycopersicoides, two species of sect. Etuberosum, and two farthest outgroups, Datura inoxia and S. dulcamara were analyzed (30 species in total; see Additional file 1). These species were chosen to cover most of the genomic groups and clades in potato, all of the species recognized in tomato [24], and appropriate outgroups. Leaf total DNA from each species was isolated using a standard CTAB protocol [45]. DNA quality and quantity were estimated by comparison with CsCl-purified $\lambda$ DNA digested with PstI on ethidium bromidestained agarose gels.

\section{Choice, amplification, and sequencing of COSII}

We tested 40 COSII loci that were putatively single copy in tomato and potato, from all 12 tomato and potato chromosomes (see Additional file 2). We screened these 40 COSII in genomic DNA of four tomato and four potato species. PCR amplifications were performed using $20 \mu \mathrm{L}$ reactions consisting of $0.1 \mu \mathrm{M}$ final concentration of each primer (see Additional file 2) and $20 \mathrm{ng}$ of template genomic DNA. Amplifications were carried out in an MJ Research DNA Engine Dyad ${ }^{\circledast}$ Peltier Thermal Cycler (Watertown, Massachusetts) using an initial denaturation at $94^{\circ} \mathrm{C}$ for $5 \mathrm{~min}$, followed by 35 cycles of $94^{\circ} \mathrm{C}$ for $30 \mathrm{~s}$, $55^{\circ} \mathrm{C}$ for $1 \mathrm{~min}, 72^{\circ} \mathrm{C}$ for $2 \mathrm{~min}$ and with a final elongation at $72^{\circ} \mathrm{C}$ for $10 \mathrm{~min}$. The reactions were run on a $1.5 \%$ agarose gel with $1 \times$ TBE buffer for 3 hours. The above PCR conditions worked for most COSII but in some cases we had to modify these PCR conditions (see Additional file $3)$.

We selected 19 of these 40 loci based on single band amplification and length of the PCR product mostly between $600-1200$ bp and with more than $60 \%$ intron content (see Additional file 3), and amplified DNA in all 30 species. To clean the product for sequencing the reaction was digested with EXO-SAP-IT ${ }^{\circledast}$ (USB Corp., Cleveland $\mathrm{OH}$ ) following the manufacturer's instructions except that reaction volumes were halved. One $\mu \mathrm{L}$ of this product was sequenced with the same primers in a $5 \mu \mathrm{L}$ reaction using the $\mathrm{ABI}$ Big Dye dideoxynucelotide termination kit (Applied Biosystem, Foster City, California). Amplifications were carried out in an MJ Research DNA Engine Dyad ${ }^{\circledR}$ Peltier Thermal Cycler (Watertown, Massachusetts) using an initial denaturation at $95^{\circ} \mathrm{C}$ for $3 \mathrm{~min}$, followed by 30 cycles of $96^{\circ} \mathrm{C}$ for $25 \mathrm{~s}, 50^{\circ} \mathrm{C}$ for $20 \mathrm{~s}$, $60^{\circ} \mathrm{C}$ for $5 \mathrm{~min}$ and with a final elongation at $72^{\circ} \mathrm{C}$ for 7 min. Excess of dye terminators were removed using CleanSeq magnetic bead sequencing reaction clean up kit from Agencourt Biosciences (Beverly, MA). Sequences were resolved on an ABI 3730xl capillary-based automated DNA sequencer (Applied Biosystems) with $50 \mathrm{~cm}$ POP-7 polymer capillaries at the Biotechnology Center of the University of Wisconsin-Madison. When a faint second band appeared or when the sequence was unreadable, the PCR product was cloned and five positive colonies were sequenced. Subsequently we learned that 18 of these 19 COSII are single copy on tomato, 12 in potato and 11 in both potato and tomato (see Additional file 3).

\section{Sequence editing and alignment}

Sequences were edited with Staden package version2003.0-beta [46] and aligned using ClustalX version 1.81 [47] at default parameters, except for the "percentage of delay divergence sequences" which was set to $15 \%$ after tests of various parameters. Further manual alignments were done in MacClade 4.06 PPC [48] minimizing the number of gaps and preferring transitions to transversions. Indels were scored by the simple gap scoring method [49] using SeqState 1.40 [50]. DNA sequences were deposited in GenBank (see Additional file 4).

\section{Phylogenetic analyses}

All analyses were conducted on three data sets: 1) a "potato data set" of 12 COSII across 11 species, nine of sect. Petota and two of sect. Etuberosum, 2) a "tomato data set" of 18 COSII across 19 species that included all species except members of sect. Petota and sect. Etuberosum, 3) the "complete data set" of 11 COSII across all 30 species. Phylogenetic analyses based on maximum parsimony were performed using PAUP* 4.0b10 [51]. The most parsimonious trees were found by heuristic searches under Fitch 
criteria and with equal weight for all characters. A heuristic search was performed using TBR branch swapping on 100,000 random taxon addition sequences. A rooted strict-consensus tree was obtained using $S$. etuberosum and S. palustre as outgroups for the potato data set, and Datura inoxia and S. dulcamara for the other two data sets. Bootstrap support [52] was estimated with 10,000 bootstrap replicates performing a TBR branch swapping on 100,000 random taxon addition sequences.

Maximum likelihood analysis was used to assess 56 models evaluated in Modeltest ver. 3.07 [53] using the Akaike Information Criterion (AIC) and hierarchical likelihood ratio test (hLRT) at $\alpha=0.01$. ML phylogeny was estimated using RAxML 7.0.3 [54] that allows each partition (each COSII) to have its own model and parameters. To evaluate the stability of clades on the optimal tree, a bootstrap analysis was performed with 100 bootstrap replicates.

Bayesian Markov chain Monte Carlo (MCMC) phylogenetic analysis [55] also was performed using MrBayes version 3.1.2 [56,57]. Model parameters for DNA data were chosen according to the criteria described above, they were estimated separately for DNA and gaps; for gaps the restriction site (binary) model was used (lset coding = variable) which accounts for the ascertainment bias produced by characters that are constant (either state 0 or 1 ) in all taxa and are not observed. Tree searching using MrBayes was performed by four runs of four linked chains ("temp" was empirically determined) for $1,100,000$ or $2,200,000$ generations with trees sampled every 100 generations. At the end of the analysis we checked that the average standard deviation of split frequencies was below 0.01 to ensure that convergence occurred properly. A conservative burn-in period was determined, and only postburn-in trees were saved. The three sets of post-burn-in trees were then combined to form a majority rule consensus tree, and this pool was taken as the best representation of the posterior distribution of tree topology and model parameters [56]. The proportion of searches in which any given node is found during the post burn-in portion of the chain constitutes the Bayesian posterior probability (PP) for that node.

The ILD test [34] was used to explore the difference in phylogenetic signal between and among data partitions, and in the potato data set was used to implement the prior agreement approach, as implemented through the partition homogeneity test in PAUP* 4.0b10 [51]. Multiple ILD tests comparing all COSII sequenced in each data set were performed and the sequential Bonferroni correction was used to control for multiple comparisons [34,58]. First, we performed one ILD test to see if all COSII sequenced in each data set can be combined together. Given that they did not pass the test, we proceeded to make all the possible pairwise comparisons within each data set to identify the COSII that were congruent. A total of 66 pairwise comparisons were made for the potato data set, 153 for the tomato data set and 55 for the potato and tomato data set. The Templeton test [59] as implemented in PAUP* 4.0b10 [51] was used to explore alternative topologies in a parsimony framework.

To assess the total evidence approach we performed a single analysis with the concatenated data set. For the prior agreement approach we were able to identify groups of COSII that gave congruent results only with the potato data set. For the consensus approach, Bayesian concordance analysis (BCA) [36] was performed in the potato and tomato data sets separately, to identify the best estimate of the phylogeny of each COSII and to create a consensus of these separate point estimates. Three different prior levels of discordance: $\alpha=1,10$, and infinite were used. For instance, an $\alpha$ value of zero corresponds to the total evidence approach that insists there is a single tree for all genes, and an infinite $\alpha$ value corresponds to an assumption of independence between gene trees. With the potato data set four independent runs with four linked chains were performed for all three $\alpha$ values; in each run with $1,100,000$ generations, 100,000 of which were discarded as the burn-in period. For heating chains, the option used was $m=50$. Runs showed good mixing and converged to the same results since the standard deviation of concordance factors was $<0.001$ in all cases.

For tomato concordance analysis, it was impossible to perform a single concordance analysis with all of the species because the trees sampled during the Bayesian analysis of four COSII (COS13b, COS1b, COS4 and COS8) were all distinct, and it was necessary to prune some species to reduce the number of trees sampled in the Bayesian analysis to assure convergence to stationary distribution within an acceptable error. For this reason, we performed three independent analyses: 1) to determine the placement of the sections that are sister to tomatoes, a concordance analysis was performed with sequence of 18 COSII in 12 OTUs that included species or allelic variants of Datura inoxia, S. dulcamara, S. lycopersicoides, S. sitiens, S. juglandifolium, S. ochranthum, S. pennellii, S. corneliomulleri, S. huaylasense-1, S. huaylasense-2, S. arcanum and S. lycopersicum. For all three $\alpha$ values, four independent runs with four linked chains were performed. In each run of 22 million generations, $10 \%$ of the generations were discarded as the burn-in period; and for heating chains we used the option $m=50$. Runs showed good mixing and converged to the same results since the standard deviation of concordance factors was $<0.005$ in each case. 2) The second concordance analysis was conducted to determine if $S$. habrochaites and $S$. pennellii are the most divergent tomato species and to determine the placement of $S$. chilense, $S$. 
corneliomulleri, and S. peruvianum. We conducted a concordance analysis with all 18 COSII and with ten OTUs $(S$. juglandifolium, S. pennellii, S. habrochaites-1, S. habrochaites-2, S. chilense-1, S. chilense-2, S. corneliomulleri, S. peruvianum-1, S. peruvianum-2, and S. lycopersicum) using the same parameters that were used for the outgroups. Runs showed good mixing (SD of concordance factors was $<0.005$ in each $\alpha$ ) 3) The last concordance analysis with the tomato data set with all 18 COSII was conducted to determine the placement of $S$. huaylasense, and to determine relationships among $S$. arcanum, S. chmielewskii, and $S$. neorickii. Four independent runs of four linked chains were performed for each $\alpha$ with seven OTUs ( $S$. pennellii, S. huaylasense-1, S. huaylasense-2, S. neorickii, S. arcanum, S. chmielewskii and S. lycopersicum).

\section{Authors' contributions}

DS conceived and designed the research and obtained funding. FR designed the research, performed the DNA extractions, generated the DNA sequences, carried out the phylogenetic analyses and wrote the manuscript. FW and ST developed the COSII markers. CA performed the concordance analyses. FR and DS revised several versions of the manuscript. CA, FW and ST reviewed the last version of the manuscript. All the authors approved the final manuscript.

\section{Additional material}

\section{Additional file 1}

Species examined; their superseries and series relationships within sect.Petota, endosperm balance number (EBN), genomes and plastid DNA clade relationships.

Click here for file

[http://www.biomedcentral.com/content/supplementary/1471-

2148-9-191-S1.doc]

\section{Additional file 2}

The 40 COSII oligonucleotide primers screened in this study.

Click here for file

[http://www.biomedcentral.com/content/supplementary/1471-

2148-9-191-S2.doc]

\section{Additional file 3}

The 19 COSII markers used in this study and their characteristics. Click here for file

[http://www.biomedcentral.com/content/supplementary/14712148-9-191-S3.doc]

\section{Additional file 4}

NCBI sequence database accession numbers.

Click here for file

[http://www.biomedcentral.com/content/supplementary/14712148-9-191-S4.doc]

\section{Acknowledgements}

This paper represents partial fulfillment of a PhD Degree for FR in Plant Breeding and Plant Genetics at the University of Wisconsin-Madison. We thank Ph.D. committee members Dennis Halterman, Shelley Jansky, and Kenneth Sytsma; and also David Baum for advice and review, and the staff of the US Potato Genebank and the C.M. Rick Tomato Genetics Resource Center for germplasm. This research was supported by the USDA and by NSF DEB 0316614 and USDA National Research Initiative Grant 200835300-18669 to David Spooner.

\section{References}

I. Hijmans R, Gavrilenko T, Stephenson S, Bamberg J, Salas A, Spooner $D M:$ Geographic and environmental range expansion through polyploidy in wild potatoes (Solanum section Petota). Global Ecol Biogeogr 2007, I 6:485-495.

2. Marks GE: Cytogenetic studies in tuberous Solanum species: I. Genomic differentiation in the Group Demissa. J Genet I955, 53:262-269.

3. Marks GE: Cytogenetic studies in tuberous Solanum species: III. Species relationships in some South and Central American species. New Phytol 1965, 64:293-306.

4. Hawkes JG: Taxonomy, cytology and crossability. In Kartoffel Volume 2. 2nd edition. Edited by: Kappert H, Rudorf W. Berlin: Paul Parey; 1958: I-43.

5. Hawkes JG: The potato. Evolution, biodiversity and genetic resources Washington, DC: Belhaven Press; 1990.

6. Irikura Y: Cytogenetic studies on the haploid plants of tuber bearing Solanum species: II. Cytogenetic investigations on haploid plants and interspecific hybrids by utilizing haploidy. (In Japanese, with English summary). Res Bull Hokkaido Nat Agric Exp Station 1976, I I 5: I-80.

7. Ramanna MS, Hermsen JGT: Structural hybridity in the series Etuberosa of the genus Solanum and its bearing on crossability. Euphytica 1981, 30:|5-31.

8. López LE, Hawkes JG: Cytology and genome constitution of the tuber-bearing Solanum species in series Conicibaccata. In Solanaceae III, Taxonomy, Chemistry and Evolution Edited by: Hawkes JG, Lester RN, Nee M, Estrada-R N. Kew, UK: Royal Botanic Gardens; 1991:327-346.

9. Matsubayashi M: Phylogenetic relationships in the potato and its related species. In Chromosome engineering in plants: genetics, breeding, evolution, Part B Edited by: Tsuchiya T, Gupta PK. Amsterdam: Elsevier Science Publishers BV; 1991:93-II8.

10. Ramanna MS, Hermsen JGT: Genome relationships in tuberbearing Solanums. In The biology and taxonomy of the Solanaceae Edited by: Hawkes G, Lester RN, Skelding AD. Linnean Society of London Ser. 7. London: Academic Press; 1979:647-654.

II. Gavrilenko T, Thieme R, Rokka V-M: Cytogenetic analysis of Lycopersicon esculentum (+) Solanum etuberosum somatic hybrids and their androgenetic regenerants. Theor Appl Genet 200I, I 03:231-239.

12. Wang Y, Diehl A, Wu F, Vrebalov J, Giovannoni J, Siepel A, Tanksley SD: Sequencing and comparative analysis of a conserved syntenic segment in the Solanaceae. Genetics 2008, 180:391-408.

13. Spooner DM, Salas A: Structure, biosystematics, and genetic resources. In Handbook of potato production, improvement, and postharvest management Edited by: Gopal J, Khurana SMP. New York: Haworth's Press, Inc. Binghampton; 2006:I-39.

14. Spooner DM, Anderson G], Jansen RK: Chloroplast DNA evidence for the interrelationships of tomatoes, potatoes, and pepinos (Solanaceae). Amer J Bot 1993, 80:676-688.

15. Olmstead RG, Palmer JD: Implications for the phylogeny classification, and biogeography of Solanum from cpDNA restriction-site variation. Syst Bot 1997, 22:19-29.

16. Olmstead RG, Sweere JA, Spangler RE, Bohs L, Palmer JD: Phylogeny and provisional classification of the Solanaceae based on chloroplast DNA. In Solanaceae IV: Advances in biology and utilization Edited by: Nee M, Symon DE, Lester RN, Jessop JP. Kew, U.K.: Royal Botanic Gardens; 1999: I I I-I37.

17. Bohs L, Olmstead RG: Solanum phylogeny inferred from chloroplast DNA sequence data. In Solanaceae IV: Advances in biology and utilization Edited by: Nee M, Symon DE, Lester RN, Jessop JP. Kew, U.K.: Royal Botanic Gardens; I999:97-I I0. 
18. Peralta IE, Spooner DM: GBSSI gene phylogeny of wild tomatoes (Solanum L. section Lycopersicon [Mill.] Wettst. subsection Lycopersicon). Amer J Bot 2001, 88: 1888-1902.

19. Spooner DM, Sytsma KJ: Reexamination of series relationships of Mexican and Central American wild potatoes (Solanum sect. Petota): Evidence from chloroplast DNA restriction site variation. Syst Bot 1992, 17:432-448.

20. Rodríguez A, Spooner DM: Chloroplast DNA analysis of Solanum bulbocastanum and $S$. cardiophyllum, and evidence for the distinctiveness of $S$. cardiophyllum subsp. ehrenbergii (sect. Petota). Syst Bot 1997, 22:3 I-43.

21. Spooner DM, Castillo R: Reexamination of series relationships of South American wild potatoes (Solanaceae: Solanum sect. Petota): evidence from chloroplast DNA restriction site variation. Amer J Bot 1997, 84:67|-685.

22. Spooner DM, Rodríguez F, Polgár Z, Ballard HE Jr, Jansky SH: Genomic origins of potato polyploids: GBSSI gene sequencing data. PI Genome, suppl Crop Sci 2008, 48(SI):S27-S36.

23. Rodríguez F, Spooner DM: Nitrate reductase phylogeny of potato (Solanum sect. Petota) genomes with emphasis on the origins of the polyploid species. Syst Bot 2009, 34:207-219.

24. Peralta IE, Spooner DM, Knapp S: The taxonomy of tomatoes: a revision of wild tomatoes (Solanum section Lycopersicon) and their outgroup relatives in sections Juglandifolium and Lycopersicoides. Syst Bot Monogr 2008, 84: I- I86.

25. Rick CM, Laterrot $\mathrm{H}$, Philouze J: A revised key for Lycopersicon species. Tomato Gen Coop Rep 1990, 40:31.

26. Peralta IE, Spooner DM: Morphological characterization and relationships of wild tomatoes (Solanum L. Section Lycopersicon). Monogr Syst Bot, Missouri Bot Gard 2005, 104:227-257.

27. Palmer JD, Zamir D: Chloroplast DNA evolution and phylogenetic relationships in Lycopersicon. Proc Natl Acad Sci USA 1982 79:5006-5010

28. Miller JC, Tanksley SD: RFLP analysis of phylogenetic relationships and genetic variation in the genus Lycopersicon. Theor Appl Genet 1990, 80:437-448.

29. Marshall JA, Knapp S, Davey MR, Power JB, Cocking EC, Bennett MD Cox AV: Molecular systematics of Solanum section Lycopersicum (Lycopersicon) using the nuclear ITS rDNA region. Theor Appl Genet 200I, I03:I216-I 222.

30. Spooner DM, Peralta IE, Knapp S: Comparison of AFLPs with other markers for phylogenetic inferences in wild tomatoes. [Solanum L. section Lycopersicon (Mill.) Wettst.]. Taxon 2005, 54:43-6I.

31. Williams DM: Combining trees and combining data. Taxon 1994, 43:449-455.

32. Huelsenbeck JP, Bull J], Cunningham : Combining data in phylogenetic analysis. Tree 1996, II:152-158.

33. Mason-Gamer RJ, Kellogg EA: Testing for phylogenetic conflict among molecular data sets in the tribe Triticeae (Gramineae). Syst Biol 1996, 45:524-545.

34. Farris JS, Källersjö M, Kluge AG, Bult C: Testing significance of congruence. Cladistics 1994, 10:315-319.

35. Baum DA: Concordance trees, concordance factors, and the exploration of reticulate genealogy. Taxon 2007, 56:417-426.

36. Ané C, Larget B, Baum DA, Smith SD, Rokas A: Bayesian estimation of concordance among gene trees. Mol Biol Evol 2007, 24:4I 2-426.

37. Wu F, Mueller LA, Crouzillat D, Pétiard V, Tanksley SD: Combining bioinformatics and phylogenetics to identify large sets of single-copy orthologous genes (COSII) for comparative, evolutionary and systematics studies: $A$ test case in the Euasterid plant clade. Genetics 2006, I74:1407-1420.

38. Gogarten JP, Olendzenski L: Orthologs, paralogs and genome comparison. Curr Opin Gen Develop 1999, 9:630-636.

39. Sonnhammer ELL, Koonin EV: Orthology, paralogy and proposed classification for paralog subtypes. Trends Gen 2002, 18:619-620.

40. Rodríguez F: Molecular phylogeny of Solanum Subgenus Potatoe, Sections Lycopersicon and Petota. In PhD thesis University of Wisconsin; Horticulture Department, Plant Breeding and Plant Genetics Program; Madison, Wisconsin; 2008.

4I. Bull JJ, Huelsenbeck JP, Cunningham CW, Swofford DL, Waddell PJ: Partitioning and combining data in phylogenetic analysis. Syst Biol 1993, 42:384-397.
42. Miyamoto MM, Fitch WM: Testing species phylogenies and phylogenetic methods with congruence. Syst Biol 1995, 44:64-76.

43. Peralta IE, Knapp S, Spooner DM: New species of wild tomatoes (Solanum section Lycopersicon: Solanaceae) from northern Peru. Syst Bot 2005, 30:24-434.

44. Zou X-H, Zhang F-M, Zhang J-G, Zang L-L, Tang L, Wang J, Sang T: Analysis of 142 genes resolves the rapid diversification of the rice genus. Genome Biol 2008, 9:R49.

45. International Potato Center (CIP): Molecular Biology Laboratory Protocols: Plant Genotyping Second edition. Edited by: Ghislain M, Zhang D, Herrera MR. Crop Improvement and Genetic Resources Department Training Manual. Lima, Peru; 1999.

46. Staden R: The Staden sequence analysis package. Mol Biotech 1996, 5:233-241.

47. Thompson JD, Gibson TJ, Plenwniak F, Jeanmougin F, Higgins DG The ClustalX Windows interface: flexible strategies for multiple sequence alignment aided by quality analysis tools. Nuc Acids Res 1997, 25:4876-4882.

48. Maddison DR, Maddison WP: MacClade 4.03: Analysis of phylogeny and character evolution Suderland, Massachusetts: Sinauer; 200I.

49. Simmons MP, Ochoterena H: Gaps as characters in sequencebased phylogenetic analyses. Syst Biol 2000, 49:369-38I.

50. Müller KF: SeqState - primer design and sequence statistics for phylogenetic DNA data sets. Appl Bioinformatics 2005, 4:65-69.

51. Swofford DL: PAUP*: Phylogenetic analysis using parsimony (*and other methods). Version 4.0b3a PPC Sunderland, Massachusetts: Sinauer Associates; 2002

52. Felsenstein J: Confidence limits on phylogenies: an approach using the bootstrap. Evolution 1985, 39:783-791.

53. Posada D, Crandall KA: MODELTEST: testing the model of DNA substitution. Bioinformatics 1998, 14:817-8|8.

54. Stamatakis A: RaxML-VI-HPC: Maximum Likelihood-based phylogenetic analysis with thousands of taxa and mixed models. Bioinformatics 2006, 22:2888-2690.

55. Yang Z, Rannala B: Bayesian phylogenetic inference using DNA sequences: a Markov Chain Monte Carlo method. Mol Bio Evol 1997, 14:717-724.

56. Huelsenbeck JP, Ronquist F: MrBayes: Bayesian inference of phylogenetic trees. Bioinformatics 200I, 17:745-755.

57. Ronquist F, Huelsenbeck JP: MrBayes 3: Bayesian phylogenetic inference under mixed models. Bioinformatics 2003, 19:1572-1574.

58. Holm S: A simple sequentially rejective multiple test procedure. Scand J Stat 1979, 6:65-70.

59. Templeton AR: Phylogenetic inference from restriction endonuclease cleavage site maps with particular reference to the evolution of humans and the apes. Evolution 1983, 37:221-244.

60. Castillo R, Spooner DM: Phylogenetic relationships of wild potatoes, Solanum series Conicibaccata (sect. Petota). Syst Bot 1997, 22:45-83.

Publish with Bio Med Central and every scientist can read your work free of charge

"BioMed Central will be the most significant development for disseminating the results of biomedical research in our lifetime. "

Sir Paul Nurse, Cancer Research UK

Your research papers will be:

- available free of charge to the entire biomedical community

- peer reviewed and published immediately upon acceptance

- cited in PubMed and archived on PubMed Central

- yours - you keep the copyright
BioMedcentral 